\title{
Anticoagulant treatment as a risk factor for primary intracerebral haemorrhage
}

\author{
R Fogelholm, K Eskola, T Kiminkinen, I Kunnamo
}

\begin{abstract}
Forty one $(14 \cdot 2 \%)$ of 288 patients with primary intracerebral haemorrhage occurring between September 1985 and December 1989 in Central Finland were on anticoagulant treatment at the onset of symptoms. In a sample of 29000 subjects from the same population the prevalence of anticoagulant treatment was $1.6 \%$ in those aged 40 years or older. The estimated age adjusted odds ratio of being on anticoagulant treatment at the time of primary intracerebral haemorrhage was 6.7 (95\% CI from 4.5 to 9.9). The risk was highest during the first year of anticoagulation. Overtreatment (thrombotest value $<5 \%$ ) was slightly more common among the patients. The haematoma volumes measured from the CT scans were similar in patients on anticoagulant treatment and those not anticoagulated. The case fatality rate during the first week and the mortality during follow up of 32 months were slightly higher, and the functional outcome slightly worse in the anticoagulated group.
\end{abstract}

(F Neurol Neurosurg Psychiatry 1992;55:1121-1124)

Bleeding complications are inherent risks of anticoagulant (AC) treatment and most of the fatal bleedings are intracranial. ${ }^{1}$ In studies on spontaneous intracerebral haemorrhage during the era of CT the prevalence of patients being on AC treatment at the onset of bleeding has varied from $9 \%-23 \% .^{2-8}$

There are two studies ${ }^{89}$ in which the magnitude of the risk of intracerebral haemorrhage during $\mathrm{AC}$ treatment has been estimated as 7.6-11 times higher than that of patients not on AC treatment. In addition, factors possiblycontributing to this increased risk have been identified, for example, the level of anticoagulation, the duration of the AC treatment, and hypertension.

The aim of this retrospective study was to estimate the magnitude of the increased risk of primary intracerebral haemorrhage $(\mathrm{PICH})$ during AC treatment, and to find out factors possibly associated with this risk. The study was based on a representative patient material with either CT or necropsy confirmation of the diagnosis, and on prevalence data of AC treatment in a sample of the same population from which the patients emerged. In addition, we compared the haematoma volumes and the outcome of patients on AC treatment with those not anticoagulated.

\section{Patients and methods}

During the period from 1 September 1985 to 31 December 1989 a total of 293 patients with $\mathrm{PICH}$ were diagnosed in a population of 245000 in Central Finland (fig 1). The diagnosis was confirmed in 237 cases by CT, and in 56 cases by necropsy. Of these patients 158 have been included in an epidemiological study on the population of 116000 living in the Jyväskylä Region, ${ }^{10}$ the other 135 patients are from other parts of Central Finland. The patients in this study were traced from: a) files of the Department of Neurology; b) discharge lists of the Central Hospital, the Health Centres, and the Department of Neurosurgery, University of Kuopio; c) lists of death certificates of Central Finland, and d) medical and medico-legal necropsy reports. The diagnosis of $\mathrm{PICH}$ excludes haemorrhages due to trauma, rupture of an arterial aneurysm or arterio-venous malformation, or bleeding from cerebral neoplasm.

On the basis of the figures from the epidemiological study from the Jyväskylä Region ${ }^{10}$ we estimated that $90 \%$ of all PICH cases aged less than 69 years, $71 \%$ aged $70-79$ years, and $50 \%$ aged 80 years or more that occurred in Central Finland during the study period were included in our analysis. Data on AC treatment, previous hypertension, stroke, and cardiac diseases was obtained in 288 patients which form the basis of this study.

The CT examinations were performed within 24 hours of onset in $43 \%$, and within 72 hours in $90 \%$ of the patients. The location of the haematomas on the CT films was assessed applying the anatomical atlas of Kretschmann and Weinrich. ${ }^{11}$ The haematoma volumes were measured from the CT films using a computer program. The area of the haemorrhage in each slice was measured planimetrically and multiplied by the thickness of the slice. The sum of these subvolumes gave the total haematoma volume.

At the end of follow up (31 August 1990) all patients who had been discharged alive were contacted by telephone, or in the case of death or severe handicap a relative or carer was interviewed. The functional outcome was assessed using the Rankin grading system, ${ }^{12}$ and the cause of death obtained from the death certificates was confirmed by data from the medical and necropsy records. 


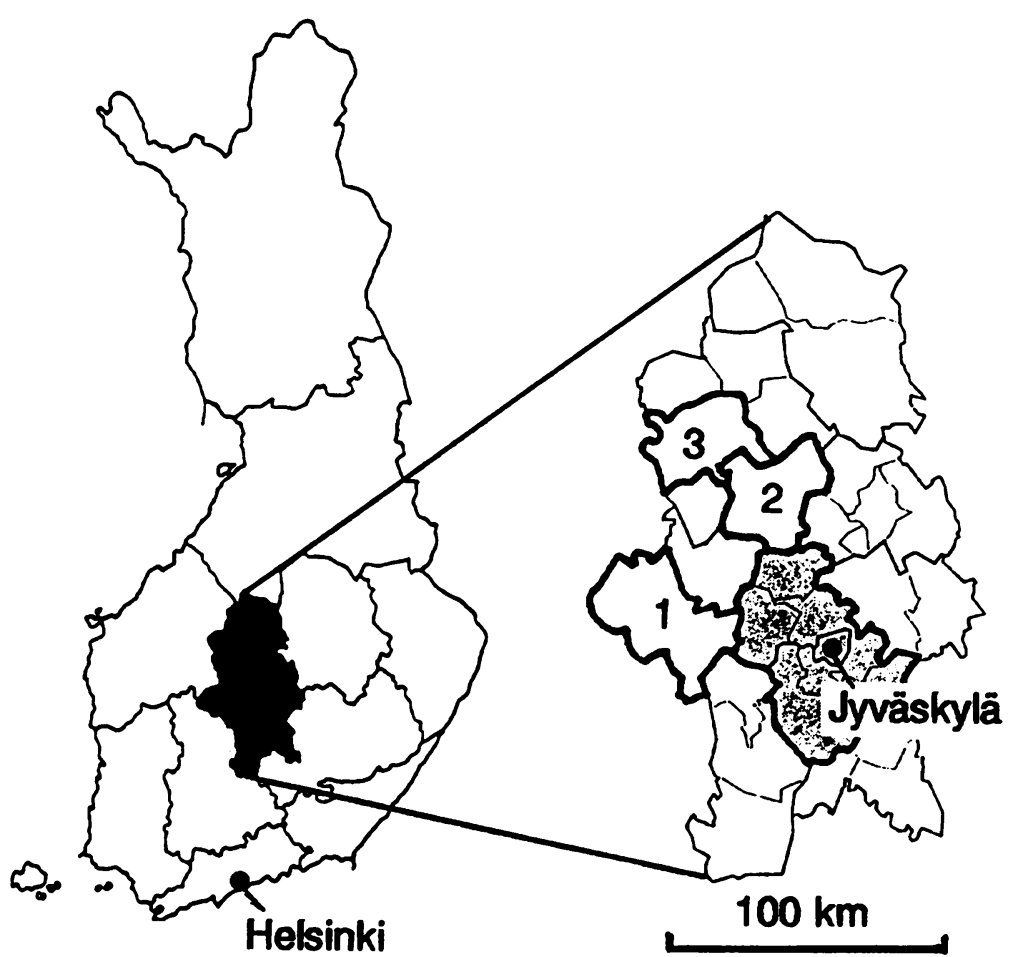

Figure 1 Map of Central Finland. The Fyväskylä Region is hatched, and the Health Centres included in the population study are numbered: $1=$ Keuruu, $2=$ Saarijärvi, and $3=$ Karstula.
Central Hospital of Central Finland, Jyväskylä.

The prevalence of AC treatment in Central Finland was estimated by collecting data on all thrombotests performed during a six to eight week period in 1989-90 by the laboratories of the Health Centres of Keuruu, Karstula and Saarijarvi (fig 1) with a total population of 29000 (12\% of the population of Central Finland). The medical records of all patients with thrombotest during the observation period were examined, and those on AC treatment were included. In cases of PICH the thrombotest value was obtained at the onset of symptoms (or the most recent value before onset) and included in the analysis.

The confidence intervals (CI) of prevalence rates were calculated using the tables of Schoenberg, ${ }^{13}$ and of the medians according to Campbell and Gardner. ${ }^{14}$ The significance of a difference between proportions was calculated by the chi-square test. The Mantel-Haenszel method was applied in calculating the summary odds ratio (OR). ${ }^{15}$

\section{Results}

Forty one $(14 \cdot 2 \%)$ of the $288 \mathrm{PICH}$ patients were on AC treatment at the onset of symptoms, and all except one were over 40 years of age (table 1). The prevalence of AC treatment in the sample population aged 40 years or older was $1.6 \%(95 \%$ CI $1 \cdot 4-1 \cdot 9)$, and there was a steady increase in the prevalence figures by age (table 2). The odds ratio of $\mathrm{PICH}$ adjusted for age of persons on AC treatment was 6.7 (95\% CI 4.5-9.9) compared with those not on AC treatment, 5.6 (95\% CI 3.3-9.6) for men and $7 \cdot 2(95 \%$ CI $4 \cdot 3-12 \cdot 1)$ for women. There was no trend in the ORs by age the values varying between 2.8 and 8.2 in the age groups over 50 years.

Table 1 Prevalence of anticoagulant treatment among patients with primary intracerebral haemorrhage in Central Finland 1985-89

\begin{tabular}{|c|c|c|c|c|c|c|c|c|c|}
\hline \multirow[b]{2}{*}{ Age } & \multicolumn{3}{|l|}{ Men } & \multicolumn{3}{|c|}{ Women } & \multicolumn{3}{|c|}{ Total } \\
\hline & No & $A C+$ & (\%) & No & $A C+$ & $(\%)$ & No & $A C+$ & (\%) \\
\hline $30-39$ & 3 & - & - & 4 & 1 & (25) & 7 & 1 & (14) \\
\hline $40-49$ & 13 & 2 & (15) & 4 & - & - & 17 & 2 & (12) \\
\hline $50-59$ & 26 & 1 & (4) & 14 & - & - & 40 & 1 & (3) \\
\hline $60-69$ & 49 & 6 & (12) & 46 & 8 & (17) & 95 & 14 & (15) \\
\hline 70-79 & 44 & 9 & (20) & 57 & 10 & (18) & 101 & 19 & (19) \\
\hline $80+$ & 4 & - & - & 24 & 4 & (17) & 28 & 4 & (14) \\
\hline Total & 139 & 18 & (13) & 149 & 23 & (15) & 288 & 41 & (14) \\
\hline
\end{tabular}

AC+ = patients on anticoagulation.

Table 2 Prevalence of anticoagulant treatment in 1989-90 in a population sample from Central Finland, aged 40 years or over

\begin{tabular}{|c|c|c|c|c|c|c|c|c|c|}
\hline \multirow[b]{2}{*}{ Age } & \multicolumn{3}{|l|}{ Men } & \multicolumn{3}{|c|}{ Women } & \multicolumn{3}{|l|}{ Total } \\
\hline & No & $A C+$ & (\%) & No & $A C+$ & (\%) & No & $A C+$ & $(\%)$ \\
\hline $\begin{array}{l}40-49 \\
50-59 \\
60-69 \\
70-79 \\
80+ \\
\text { Total }\end{array}$ & $\begin{array}{r}1912 \\
1686 \\
1360 \\
796 \\
231 \\
5985\end{array}$ & $\begin{array}{r}5 \\
23 \\
34 \\
31 \\
12 \\
106\end{array}$ & $\begin{array}{l}(0.3) \\
(1 \cdot 4) \\
(2 \cdot 5) \\
(3 \cdot 9) \\
(5 \cdot 2) \\
(1 \cdot 8)\end{array}$ & $\begin{array}{r}1825 \\
1692 \\
1799 \\
1282 \\
573 \\
7171\end{array}$ & $\begin{array}{r}2 \\
8 \\
31 \\
39 \\
22 \\
102\end{array}$ & $\begin{array}{l}(0.1) \\
(0.5) \\
(1.7) \\
(3.0) \\
(3 \cdot 8) \\
(1.4)\end{array}$ & $\begin{array}{r}3737 \\
3378 \\
3159 \\
2078 \\
804 \\
13156\end{array}$ & $\begin{array}{r}7 \\
31 \\
65 \\
70 \\
34 \\
208\end{array}$ & $\begin{array}{l}(0 \cdot 2) \\
(0 \cdot 9) \\
(2 \cdot 1) \\
(3 \cdot 4) \\
(4 \cdot 2) \\
(1 \cdot 6)\end{array}$ \\
\hline
\end{tabular}

No $=$ number of persons

$\mathrm{AC}+=$ number of patients on anticoagulation 
The indications of AC treatment of the PICH patients and the population sample were similar (table 3 ).

The average duration of AC treatment of patients with $\mathrm{PICH}$ was shorter than in the population; $44 \%$ of the PICH patients had been on AC treatment for less than 1 year, half of these for less than 4 months, compared with $19 \%$ of the population sample (fig 2). Conversely, long-term treatment ( $>5$ years) was more common in the population sample. The trend was statistically highly significant $\left(\chi^{2}=\right.$ $19.0 \mathrm{df}=5 \mathrm{p}=0.002$ ).

The most recent thrombotest before onset of PICH was measured in $76 \%$ of patients within two weeks, most often on the day of onset. Overtreatment (thrombotest $<5 \%$ ) was slightly more common among PICH patients (4/41) than among the population sample $(6 / 208)\left(\chi^{2}=4 \cdot 2 \mathrm{p}=0.04\right)$.

Lobar and posterior fossa haematomas were slightly more frequent in PICH patients on AC treatment but deep basal ganglionic haematomas were more common in patients not on AC treatment. Twenty seven $(66 \%)$ of the AC

Table 3 Indications for anticoagulant treatment in patients with primary intracerebral haemorrhage, and in the population sample

\begin{tabular}{|c|c|c|c|c|}
\hline \multirow[b]{2}{*}{ Indication } & \multicolumn{2}{|c|}{$P I C H(N=41)$} & \multicolumn{2}{|c|}{ Population $(N=208)$} \\
\hline & No & $(\%)$ & No & $(\%)$ \\
\hline $\begin{array}{l}\text { Cardiac disease } \\
\text { - Atrial fibrillation } \\
\text { - MI/CHD } \\
\text { - Valvular disease } \\
\text { - Other } \\
\text { Cerebrovascular disease } \\
\text { Deep vein thrombosis/ pulmonary embolism } \\
\text { Ophthalmic artery/vein thrombosis } \\
\text { Miscellaneous }\end{array}$ & $\begin{array}{r}30 \\
27 \\
1 \\
1 \\
1 \\
5 \\
3 \\
5 \\
2\end{array}$ & $\begin{array}{r}(73) \\
(66) \\
(2) \\
(2) \\
(2) \\
(12) \\
(7) \\
(12) \\
(5)\end{array}$ & $\begin{array}{r}151 \\
103 \\
21 \\
15 \\
12 \\
30 \\
39 \\
10 \\
7\end{array}$ & $\begin{array}{r}(73) \\
(50) \\
(10) \\
(7) \\
(6) \\
(14) \\
(19) \\
(5) \\
(3)\end{array}$ \\
\hline
\end{tabular}

MI = myocardial infarction; $\mathrm{CHD}=$ coronary heart disease; $\mathrm{PICH}=$ primary intracerebra haemorrhage; POPULATION = population sample.

The totals exceed the number of patients because of two or more simultaneous indications of anticoagulation in some patients.

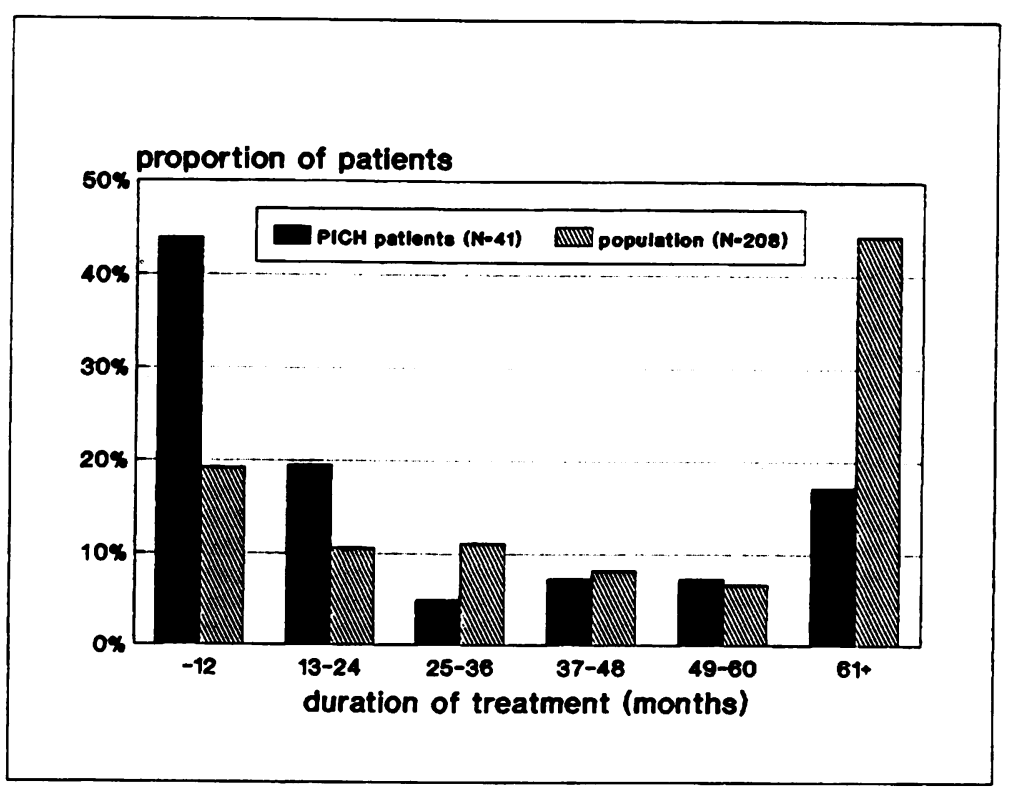

Figure 2 Distribution of patients with primary intracerebral haemorrhage (PICH), and of the population sample from Central Finland, aged over 40 years, by duration of anticoagulant treatment. treated, and $206(83 \%)$ of the non-anticoagulated PICH patients had CT examination. The median haematoma volume was $24 \mathrm{ml}(95 \%$ CI $11-49 \mathrm{ml})$ in patients on AC treatment, and $23 \mathrm{ml}(95 \% \mathrm{CI} 19-34 \mathrm{ml})$ in those not anticoagulated, the corresponding figures of patients dying within 7 days of onset were $62 \mathrm{ml}(95 \% \mathrm{CI} 16-140 \mathrm{ml})$ and $73 \mathrm{ml}$ (95\% CI $57-86 \mathrm{ml})$. The thrombotest values and the haematoma volumes did not correlate ( $\mathrm{n}=27 \mathrm{r}=0.14 \mathrm{p}=0.5$ ).

Coronary heart disease, congestive heart failure, atrial fibrillation, and ischaemic cerebrovascular disease were statistically significantly more prevalent in patients on AC treatment (table 4), and was readily explained by selection due to the indications of anticoagulant treatment. The CT confirmed location of the previous ischaemic brain infarction was the same as the present haemorrhage in only $5 / 13$ $(38 \%)$ of the cases.

The case fatality rate during the first week after onset was $54 \%$ among the AC treated, and $40 \%$ among the non-anticoagulated, and after a median follow up of 32 months was $71 \%$ of the AC treated, and $61 \%$ of those nonanticoagulated. The differences were nonsignificant. The functional outcome at the end of follow up, assessed by the Rankin grading system was similar in both patient groups, half of the patients being independent (Ranking groups 1 and 2) in the ADL. Poor outcome (Ranking grade 5) was, however, more common among the AC treated than the nonanticoagulated (2/12 and 4/97), a statistically non-significant difference.

\section{Discussion}

1 Comparison with population data

The 288 PICH patients included in this study can be considered fairly representative of the disease as it occurs in the population, especially in those under the age of 80 years. A more difficult question is how well the chosen population sample from the three Health Centres represents the population of Central Finland. Because the distribution of the indications of anticoagulant treatment and the thrombotest values were quite similar in these Health Centres it is assumed that they are a fairly good representation of the whole of Central Finland, the catchment area of the Central Hospital. On the other hand, the age and sex adjusted prevalence rates of $A C$ treatment for those aged 40 years or over varied between $1 \cdot 14 \%$ and $1.88 \%$ in the chosen Health Centres, and this indicates the presence of possible differences in the use of anticoagulants.

The age adjusted OR 6.7 obtained in our study agrees with earlier reports. ${ }^{89}$ Age had no impact on the ORs, as previously reported. ${ }^{8}$ The duration of the AC treatment was more often less than 1 year in PICH patients compared with the population sample. Similar accumulation of intracerebral haemorrhages in the first year of treatment has been observed in earlier studies. ${ }^{7916}$ In one of these studies, however, the mean duration of AC treatment 
Table 4 Prevalence of cardiovascular disease, including ischaemic brain infarction in the case history of patients with primary intracerebral haemorrhage, by anticoagulant status

\begin{tabular}{|c|c|c|c|c|}
\hline \multirow[b]{2}{*}{ Disease } & \multicolumn{2}{|l|}{$A C+$} & \multicolumn{2}{|l|}{$A C-$} \\
\hline & $N=41$ & $(\%)$ & $N=247$ & $(\%)$ \\
\hline $\begin{array}{l}\text { Hypertension } \\
\text { Coronary heart disease } \\
\text { - myocardial infarction } \\
\text { Congestive heart failure } \\
\text { Atrial fibrillation } \\
\text { IBI }\end{array}$ & $\begin{array}{r}22 / 41 \\
13 / 41 \\
6 / 41 \\
15 / 40 \\
26 / 38 \\
13 / 40\end{array}$ & $\begin{array}{l}(54) \\
(32) \\
(15) \\
(38) \\
(68) \\
(33)\end{array}$ & $\begin{array}{l}98 / 245 \\
33 / 245 \\
10 / 245 \\
40 / 245 \\
23 / 245 \\
20 / 245\end{array}$ & $\begin{array}{l}(40) \\
(14)^{\star} \\
(4)^{\star} \\
(16)^{\star} \\
(9)^{\star \star} \\
(8)^{\star \star}\end{array}$ \\
\hline
\end{tabular}

$\star=\mathrm{p}<0.01 ;{ }^{\star}=\mathrm{p}<0.001$

$\mathrm{AC}+=$ on anticoagulation; $\mathrm{AC}-=$ not anticoagulated; $\mathrm{IBI}=$ ischaemic brain infarction

before the haemorrhage was longer than that of all AC treated patients. In one prospective study $^{1}$ with patients anticoagulated for various reasons, most of the major bleeding complications also occurred during the first month of treatment. Overtreatment has been associated with increased risk of intracerebral haemorrhage, ${ }^{816}$ and also in our study overtreatment was three times as common among the PICH patients as in the population sample. Most of the patients were, however, within therapeutic range, in some, ${ }^{7-9}$ but not all ${ }^{16}$ earlier studies. The indications of AC treatment of the PICH patients were similar with the population sample. The true magnitude of the risk of PICH in patients anticoagulated for various indications can be estimated only by randomised controlled prospective studies. ${ }^{17}$ After strict exclusion criteria in non-valvular atrial fibrillation, $\mathrm{PICH}$ has been described as three times higher than in patients not anticoagulated. ${ }^{18}$ Our observations suggest that the risk is approximately sevenfold, and is especially high during the first year of treatment.

\section{Comparison of anticoagulated with non-anticoagulated $\mathrm{PICH}$ patients}

The higher prevalence of cardio- and cerebrovascular diseases, except hypertension, among the AC treated patients can be explained solely by the indications of AC treatment. One point of interest is that the location of the previous ischaemic brain infarction, diagnosed by CT, was the same as the $\mathrm{PICH}$ in only one third of cases, a finding similar to a recent study. ${ }^{7}$ This finding does not support the theory of weakened vascular wall after ischaemia.

The haematoma volumes measured from the CT films were similar regardless of anticoagulant status when all cases were included, as well as when the patients dying within the first week of onset, were analysed separately. This is in contrast to earlier studies of AC treated patients reported to have larger haematomas. ${ }^{79}{ }^{16}$ The higher proportion of AC treated cases $(34 \%)$ compared with the non-anticoagulated cases (17\%) diagnosed at necropsy may distort the volume analysis. Large haematomas have a high early case fatality rate and thus may escape CT examination and volume measurement. Similar to an earlier study, ${ }^{9}$ the thrombotest values did not correlate with the haematoma volumes. In one other study, however, larger haematomas were associated with a more intense anticoagulation. ${ }^{7}$
The trend of poorer short and long-term survival and functional outcome of the AC treated patients confirms the earlier observations. ${ }^{89}$ In one study the case fatality rate of the anticoagulated patients was even twice that of the non-anticoagulated. ${ }^{7}$

To minimise the risk of PICH during AC treatment the indications for starting treatment should be stringent. Overtreatment should be avoided, and the duration of the treatment should be as short as possible. ${ }^{19}$ Low intensity anticoagulation might also significantly reduce the number of intracerebral haemorrhages, ${ }^{20}$ and in elderly patients all contraindications, concomitant diseases, and medications should be carefully considered. ${ }^{2122}$ If the patient, however, suffers from a PICH, the outcome seems no worse than in patients without AC treatment.

We are grateful to Cees L Franke, (Heerlen) and Jan-Edvin Olsson, (Linköping) for their valuable comments during the preparation of this manuscript.

1 Landefeld CS, Goldman L. Major bleeding in outpatients treated with warfarin: Incidence and prediction by factors known at the start of outpatient therapy. $\mathrm{Am} \mathcal{F} \mathrm{Med}$ 1989;87:144-52.

2 Helweg-Larsen S, Sommer W, Strange P, Lester J, Boysen G. Prognosis for patients treated conservatively for spontaneous intracerebral hematomas. Stroke 1984;15: 1045-8

3 Foulkes MA, Wolf PA, Price TR, Mohr JP, Hier DB. The Stroke Data Bank: Design, methods, and baseline characteristics. Stroke 1988;19:547-54.

4 Bewermeyer H, Hojer C, Szelies B, Haupt WF, Neveling M, Heiss W-D. Die spontane Ponsblutung. Eine Analyse von 38 Fällen. Nervenarzt 1988;59:640-6.

5 Thie A, Spitzer K, Lappe H, Kunze K. Prognostische Bedeutung initialer klinischer und apparativer Parameter bei spontanen intrazerebralen Blutungen. Fortschr Neurol Psychiat 1988;56:163-9.

6 Inzitari D, Giordano GP, Ancona AL, Pracucci G, Mascalchi M, Amaducci L. Leukoaraiosis, intracerebral hemorrhage, and arterial hypertension. Stroke 1990;21: 1419-23.

7 Rådberg JA, Olsson JE, Rådberg CT. Prognostic parameters in spontaneous intracerebral hematomas with special reference to anticoagulant treatment. Stroke 1991;22: 571-6.

8 Wintzen AR, de Jonge $H$, Loeliger EA, Bots GTAM. The risk of intracerebral hemorrhage during oral anticoagu-
lant treatment: A population study. Ann Neurol 1984; la:553-8.

9 Franke CL, de Jonge J, van Swieten JC, Op de Coul AAW, van Gijn J. Intracerebral hematomas during anticoagulant treatment. Stroke 1990;21:726-30.

10 Fogelholm $R$, Nuutila M, Vuorela A-L. Primary intracerebral haemorrhage in the Jyväskylä Region, Central Finland, 1985-89. Incidence, case fatality rate, and functional outcome. I Neurol Néurosurg Psychiatry 1992;55:546-52.

11 Kretschmann HJ, Weinrich W. Neurounatomy and cranial computed tomography. New York: Thieme, 1986.

12 Rankin J. Cerebral vascular accidents in patients over the age of 60: II Prognosis. Siot Med f 1957;2:200-15.

13 Schoenberg BS. Calculating confidence intervals for rates and ratios. Neuroepidemiology 1983;2:257-65.

14 Campbell MJ, Gardner MJ. Calculating confidence intervals for some non-parametric analyses. In: Gardner MJ, Altman DG, eds. Statistics evith ionfidence. Confidence Altman DG, eds. Statistics evith confidence. Confidence
intervals and statistical guidelines. London: BMJ, 1989: intervals

15 Schlesselman JJ. Case-control studics. Disign. conduct, analysis. New York: Oxford University Press, 1982; 183-207.

16 Kase CS, Robinson RK, Stein RW, it al. Anticoagulantrelated intracerebral hemorrhage. Niurology 1985;35: 943-8.

17 Boysen G, Petersen P. Intracerebral hematomas during anticoagulant treatment. Strok: 1991;22:281.

18 Albers GW, Sherman DG, Gress DR, Paulseth JE, Petersen P. Stroke prevention in nonvalvular atrial fibrillation: A review of prospective randomised trials. Ann Neurol 1991;30:511-18.

19 Mattle HP. Cerebral haemorrhage and anticuagulants. Irish Med F 1990;83:44.

20 Albers GW. Intensity of anticoagulant treatment and risk of intracerebral hematoma. Stroke 1990;21:1758.

21 Lowe GDO. Anticoagulant drugs in the elderly: valuable in selected patients. $B M \mathcal{F} 1988 ; 297: 1260-2$.

22 Scott PJW. Anticoagulant drugs in the elderly: the risks usually outweigh the benefits. $B M \mathcal{F}^{1988 ; 297: 1261-3}$. 